\title{
PEMANFAATAN TEKNIK RGB PADA CITRA SATELIT HIMAWARI-8 UNTUK ANALISIS DINAMIKA ATMOSFER KEJADIAN BANJIR LAMPUNG 20 - 21 FEBRUARI 2017
}

\author{
Jaka Anugrah Ivanda Paski ${ }^{1^{*}}$, Alpon Sepriando ${ }^{2}$ Dyah Ajeng Sekar Pertiwi ${ }^{3}$ \\ ${ }^{1}$ Bidang Meteorologi Pusat Penelitian dan Pengembangan BMKG \\ ${ }^{2}$ Sub Bidang Pengelolaan Citra Satelit Cuaca BMKG \\ ${ }^{3}$ Stasiun Meteorologi Radin Inten II Lampung \\ *Email: jaka.paski@yahoo.com
}

\begin{abstract}
ABSTRAK
Teknik RGB (Red-Green-Blue) merupakan salah satu teknik intepretasi citra satelit dengan mengombinasikan beberapa kanal secara tumpang tindih warna merah, hijau dan biru untuk menyajikan informasi yang lebih mudah dipahami. Teknik RGB dapat digunakan dalam kajian analisis cuaca, terutama untuk mengidentifikasi kondisi khusus seperti bencana hidrometeorologi. Kejadian banjir pada tanggal 20 - 21 Februari 2017 yang merendam sekurangnya 7 kabupaten dan 1 kota di Provinsi Lampung yang dindikasikan terjadi karena hujan ekstrim yang merata di wilayah Lampung. Hasil pelaporan curah hujan di stasiun Klimatologi Masgar terukur $107.0 \mathrm{~mm} / \mathrm{hari}$, Pos Pengamatan Politeknik Negeri Lampung terukur $159.6 \mathrm{~mm} / \mathrm{hari}$ dan Pos Pengamatan Kemiling Bandar Lampung terukur $154.0 \mathrm{~mm} / \mathrm{hari}$ dimana curah hujan termasuk dalam kategori hujan sangat lebat BMKG (> $100 \mathrm{~mm} / \mathrm{hari}$ ). Hasil analisis kondisi regional menunjukan adanya tekanan udara rendah di barat lampung dan daerah konvergensi serta shearline di Lampung bagian barat dan tengah. Analisis citra satelit menunjukan adanya kumpulan awan dengan suhu puncak yang sangat dingin, teknik RGB menggunakan identifikasi mikrofisis atmosfer pada malam hari (Night Microphysics) dan sebaran massa udara (Air Mass) menunjukan adanya proses mikrofisis yang intensif serta aliran massa udara penyebab awan hujan yang tumbuh dan meluas di wilayah Lampung sebelum dan saat terjadinya banjir. Hasil produk olahan HCAI (Highresolution Cloud Analysis Information) menunjukan awan didominasi oleh awan Comulonimbus ( $\mathrm{Cb}$ ) dan awan konvektif padat (Dense Cloud).
\end{abstract}

Kata kunci: banjir, satelit, RGB, Night Microphysics, Air Mass

\begin{abstract}
RGB technique (Red-Green-Blue) is one of the satellite image interpretation techniques which combine multiple channels in overlapping red, green and blue to present information that is easier to understand. RGB technique can be used in the study of weather analysis primarily to identify the specific conditions such as hydrometeorological disasters. The incidence of floods on 20 to 21 February 2017 soaked for at least seven regions and a city in the province of Lampung, which was indicated to occur due to extreme rainfall. Total rainfall reported at the Station Climatological Masgar is $107.0 \mathrm{~mm} /$ day, Observation Post Politeknik Negeri Lampung was measured as $159.6 \mathrm{~mm} /$ day and Observation Post Kemiling Bandar Lampung measured 154.0 $\mathrm{mm} /$ day, where rainfall is categorized as very heavy rain according to BMKG (> $100 \mathrm{~mm} /$ day). The results of the regional analysis conditions showed a lower air pressure area, convergence and shearline in western and central Lampung region. Analysis of satellite imagery showed a collection of clouds with the very cold cloud top temperature at top, the RGB technique identification using Night Microphysics and the distribution of air masses (Air Mass) showed the process of intensive microphysics and mass air flow which then caused rain clouds that grew and extended over Lampung region before and during floods. Results of products HCAI (High-resolution Cloud Analysis Information) showed the cloud was dominated by Comulonimbus (Cb) and solid convective clouds (Dense Cloud).
\end{abstract}

Keywords: floods, satellite, RGB, Night Microphysics, Air Mass 


\section{PENDAhUluan}

Banjir adalah suatu peristiwa terjadinya peluapan air yang berlebihan pada suatu wilayah (Puslitbang BMKG, 2009). Faktor penyebab banjir dapat terjadi karena kombinasi berbagai faktor yang kompleks tetapi di daerahdaerah sekitar khatulistiwa dimana kontribusi hujan monsun dianggap cukup besar. Banjir dapat terjadi akibat naiknya permukaan air lantaran curah hujan yang diatas normal, perubahan suhu, tanggul/bendungan yang bobol, pencairan salju yang cepat, terhambatnya aliran air di tempat lain, sedangkan diperkotaan genangan lokal terjadi pada saat musim hujan, skala banjir yang terjadi cukup besar dan belum dapat dikendalikan secara dominan (Sebastian, 2008). Faktor-faktor yang mempengaruhi kerusakan akibat banjir, antara lain: besar banjir; kecepatan aliran air; dan periode kejadian banjir (Harsa dkk, 2011).

Pada tanggal 20 Februari 2017 sore hari terjadi hujan sangat lebat disertai petir di wilayah Lampung hingga dini hari tanggal 21 Februari 2017. Menurut laporan Harian Tribun Lampung, hujan deras yang mengguyur Lampung mengakibatkan banjir di sejumlah wilayah dengan setidaknya terdapat 8 daerah yang diterjang banjir, yakni Pesawaran, Pringsewu, Bandar Lampung, Lampung Utara, Lampung Selatan, Lampung Timur, Tulang bawang dan Lampung Tengah. Pesawaran menjadi lokasi banjir terparah. Berdasarkan laporan Badan Penanggulangan Bencana Daerah (BPBD) air menggenangi 1.000-an rumah warga. Kerugian banjir juga menyebabkan seorang korban jiwa akibat terseret arus banjir. Mengacu pada UndangUndang Nomor 31 tahun 2010 dan Peraturan KBMKG Nomor :KEP.009 tahun 2010 tentang SOP Pelaksanaan Peringatan Dini, Pelaporan, dan Diseminasi Cuaca Ekstrim. Oleh karena itu diperlukan pemahaman dinamika atomosfer dan lautan, utamanya dalam hal proses pembentukan uap air, awan, curah hujan dan proses pelepasan panas laten ke atmosfer oleh klaster awan-awan penghasil hujan yang sangat besar, yang kemudian akan mempengaruhi sirkulasi atmosfer global (BMKG, 2010). Tulisan ini bertujuan untuk mengetahui keadaan dinamika atmosfer saat terjadi fenomena cuaca ekstrim penyebab banjir di Lampung tanggal 20-21 Februari 2017 dengan cara memanfaatkan citra satelit Himawari-8.
Kehadiran satelit Himawari-8 pada tahun 2015 dengan resolusi temporal 10 menit dan memiliki 16 kanal sebagai generasi pembaruan dari MTSAT-2 (Multi Tranpose Satellite-2) membuat pengamatan pertumbuhan awan konvektif dengan satelit dapat lebih detail (JMA, 2015). Satelit Himawari 8 sebagai generasi baru dari satelit MTSAT-2 dilengkapi sensor bernama Advanced Himawari Imager (AHI), yang memiliki resolusi temporal, spektral dan spasialnya lebih baik dibandingkan seri sebelumnya. Kanal pada Himawari-8 terdiri dari 3 kanal visibel, 3 kanal infra merah-dekat atau near infrared (NIR) dan 10 kanal Infrared (IR). Untuk resolusi spasial pada Himawari-8 terdiri dari $0.5 \mathrm{~km}$ dan $1 \mathrm{Km}$ untuk kanal cahaya tampak (visible), $2 \mathrm{~km}$ untuk data kanal IR serta $1 \mathrm{~km}$ dan $2 \mathrm{~km}$ untuk data kanal NIR. Setiap panjang gelombang memiliki kegunaan dan karakteristik tersendiri (table 1). Untuk resolusi temporal, Himawari-8 memiliki resolusi tiap 10 menit untuk pengamatan global dan 2,5 menit sekali untuk pengamatan khusus (Pandjaitan, 2015). Dengan banyaknya kanal yang tersedia itu pada satelit Himawari 8, maka para penggunanya dapat membuat produk RGB (red green blue) dengan mengkombinasikan beberapa kanal (Kushardono, 2012).

RGB (Red-Green-Blue) merupakan satu teknik intepretasi memanfaatkan konsep model warna dimana suatu warna dihasilkan untuk menganalisis kondisi tertentu yang ada berasal dari 3 warna primer (primary colour) yaitu merah (red), hijau (green), dan biru (blue). Kombinasi dari 3 warna primer tersebut menghasilkan warna-warna turunan (secondary colour) kuning, magenta, cyan, coklat, hitam dan putih. Dalam pengolahan data citra satelit, teknik RGB digunakan untuk menggabungkan beberapa kanal panjang gelombang yang berbeda agar mendapatkan suatu produk citra yang berisi informasi yang lebih baik daripada yang didapatkan dari citra 1 kanal saja. Ada beberapa produk teknik RGB yang dapat digunakan untuk menganalisis dinamika atmosfer pada kejadian hujan ekstrim antara lain Air Mass yang digunakan untuk menganalisis pergerakan masa udara dan Night Microphysics yang digunakan untuk menganalisis proses mikrofisis awan dimana terjadi pelepasan energi (panas laten) dari uap air menjadi inti kondensasi dan butiran (tetes) air, adanya penyerapan molekul air pada inti 
kondensasi dan penggabungan antara butiran di dalam awan. Seseuai dengan namanya Night Microphysics digunakan untuk analisis pada malam hari.

Tabel 1. Karakteristik Kanal Panjang Gelombang pada AHI (Pandjaitan, 2015).

\begin{tabular}{|c|c|c|c|c|}
\hline $\begin{array}{c}\text { Jenis } \\
\text { Panjang } \\
\text { Gelombang }\end{array}$ & Kanal & $\begin{array}{c}\text { Panjang } \\
\text { Gelombang } \\
\text { Tengah }(\mu \mathrm{m})\end{array}$ & $\begin{array}{c}\text { Resolusi } \\
(\mathrm{km})\end{array}$ & Contoh Penggunaan \\
\hline \multirow{3}{*}{ vIS } & 1 & 0.47 & 1 & Daytime aerosols di daratan, coastal water mapping \\
\hline & 2 & 0.51 & 1 & $\begin{array}{l}\text { Water/ocean color, termasulk deteks terhadap algal blooms; } \\
\text { memungkinkan true color imagery ketika dikombinaskan } \\
\text { dengan kanal biru dan merah (Kanal visible } 1 \text { dan } 3)\end{array}$ \\
\hline & 3 & 0.64 & 0.5 & Daytime cloud, kabut, insolasi, angin \\
\hline \multirow{3}{*}{ Near-IR } & 4 & 0.86 & 1 & $\begin{array}{l}\text { Daytime vegetation, bekas kebakaran, aerosol sepanjang } \\
\text { perairan, angin }\end{array}$ \\
\hline & 5 & 1.6 & 2 & Fase Daytime cloud-topdan ukuran partikel, salju \\
\hline & 6 & 2.3 & 2 & $\begin{array}{l}\text { Daytime land/cloud properties, ukuran partikel, vegetasi, } \\
\text { salju }\end{array}$ \\
\hline SW IR & 7 & 3.9 & 2 & Permukanan dan awan, kabut pada malam hari, api, angin \\
\hline \multirow[b]{2}{*}{$\mathrm{IR}(\mathrm{WV})$} & $\frac{8}{9}$ & $\frac{6.2}{6.9}$ & $\frac{2}{2}$ & $\begin{array}{l}\text { Uap air atmosfer level tinggi, angin, curah hujan } \\
\text { Uap air atmosfer level menengah, angin, curah hujan }\end{array}$ \\
\hline & 10 & 7.3 & 2 & Uap air level rendah, angin, $\mathrm{SO}_{2}$ \\
\hline \multirow{6}{*}{$L W \mathbb{R}$} & 11 & 8.6 & 2 & $\begin{array}{l}\text { Total water untuk stablitas, fase awan, dust, SO2, curah } \\
\text { hujjan }\end{array}$ \\
\hline & 12 & 9.6 & 2 & Total column osone, turbulensi, angin \\
\hline & 13 & 10.4 & 2 & Permukaan dan awan \\
\hline & 14 & 11.2 & 2 & Imagen, sea surface temperature (SST), awan, curah hujan \\
\hline & 15 & 12.4 & 2 & Total column water vapor, ash, SST \\
\hline & 16 & 13.3 & 2 & Suhu udara, tinggi dan jumlah awan \\
\hline
\end{tabular}

\section{DATA DAN METODE}

Data yang digunakan dalam analisis terdiri dari data:

a. Data satelit Himawari-8 kanal $7(3.9 \mu \mathrm{m})$, kanal $8(6.2 \mu \mathrm{m})$, kanal $10(7.3 \mu \mathrm{m})$, kanal $12(9.6 \mu \mathrm{m})$, kanal $13(10.4 \mu \mathrm{m})$ dan kanal $15(12.3 \mu \mathrm{m})$ untuk tanggal 20 Februari 2017 dalam format sataid (.z) dari subbid pengelolaan citra satelit BMKG .

b. Data produk HCAI satelit Himawar-8 pada 20 Februari 2017.

c. Data laporan curah hujan harian stasiun dan pos hujan di Lampung, serta pertiga jam Stasiun.

d. Meteorologi Radin Inten II Lampung

e. Produk Streamline dari http://bom.gov.au.

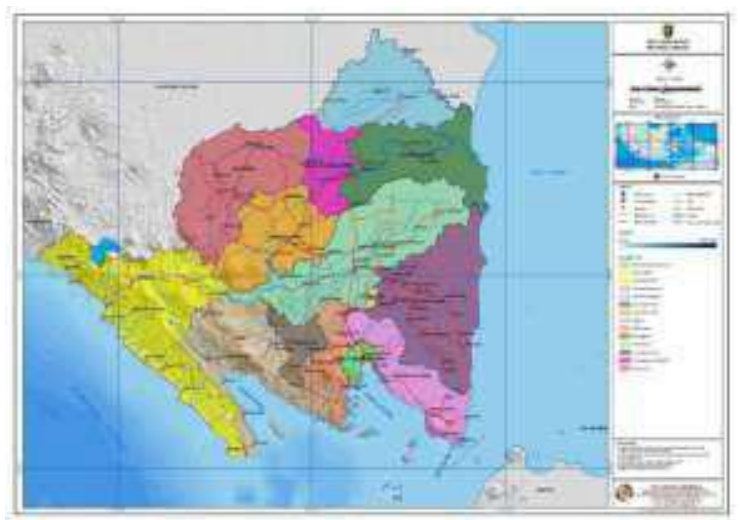

Gambar 1. Lokasi penelitian.
Metode analisis satelit yang dijalankan menggunakan perangkat lunak Sataid GMSLPD. SATAID (Satellite Animation and Interactive Diagnosis) adalah satu perangkat lunak yang dijalankan di dalam sistem operasi Windows yang berfungsi untuk mengolah data binary dari satelit menjadi gambar citra. Saat ini SATAID telah digunakan sebagai alat operasional di JMA untuk analisis cuaca harian, termasuk pula dalam kegiatan monitoring siklon tropis. Ada beberapa variasi program SATAID seperti GMSLPD yang dikhususkan untuk analisis siklon tropis (Tanaka, 2009).

Untuk lokasi penelitian dapat dilihat pada gambar 1. Untuk pengaturan dari teknik RGB pada Night Microphysics menggunakan pengaturan Red (IR12.3 $\mu \mathrm{m}$ - IR10.4 $\mu \mathrm{m}$ ), Green (IR10.4 $\mu \mathrm{m}$ - NIR3.9 $\mu \mathrm{m}$ ), Blue (IR 10.4 $\mu \mathrm{m})$. Pada Air Mass menggunakan pengaturan Red (WV6.2 $\mu \mathrm{m}$ - WV7.3 $\mu \mathrm{m}$ ), Green (IR9.7 $\mu \mathrm{m}$ - IR10.8 $\mu \mathrm{m}$ ), Blue (WV6.2 $\mu \mathrm{m}$ ) (JMA, 2015). Pengaturan RGB dan penggunaan kanal disesuaikan dengan karakteristik fenomena yang diamati, terdapat rentang nilai yang digunakan untuk setiap kanal dan juga penetapan gamma.

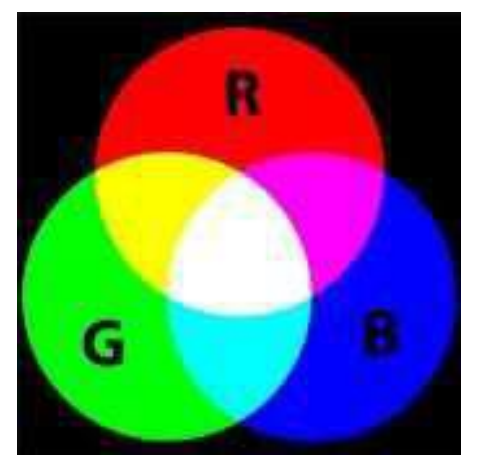

Gambar 2. Kombinasi dasar RGB.

\section{HASIL DAN PEMBAHASAN}

3.1 Analisis kondisi spasial

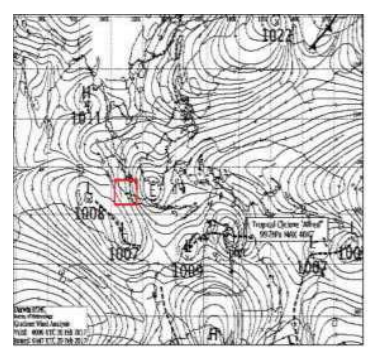

(a)

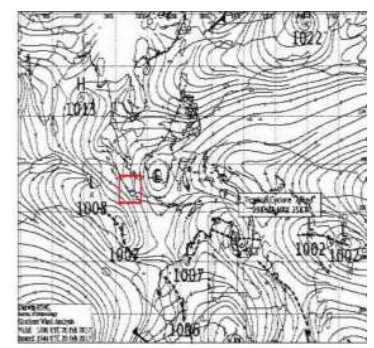

(b)
Gambar 3. Peta streamline angin pada tanggal 20 Februari 2017 (a) 00.00 UTC dan (b) 12.00 UTC (Sumber: BoM). 
Berdasarkan analisis angin gradien pada tanggal 20 Februari pukul 00.00 UTC yang di keluarkan oleh Bureau of Meteorology (BoM) bahwa adanya dua pusat tekanan rendah di barat dan selatan Lampung, serta sirkulasi Eddy di timur dengan menyebabkan terdapatnya daerah perubahan arah angin (shearline) dan pertemuan aliran massa udara (konvergensi) di wilayah samudra Hindia sebelah barat Lampung (kotak merah gambar 3a). Pada analisis pukul 12.00 UTC pusat tekanan rendah dan sirkulasi Eddy masih terjadi sehingga wilayah Lampung masih terdapat arah angin (shearline) dan pertemuan aliran massa udara (konvergensi) namun sudah berpindah di wilayah Lampung bagian barat sehingga selatan (kotak merah gambar 3b). Perubahan arah angin (shearline) dan konvergensi di wilayah Lampung mempengaruhi pertumbuhan awan yang signifikan dan bertahan hingga waktu yang lama.

\section{a. Analisis Curah Hujan}

Kejadian banjir dilaporkan mulai menggenang pada malam tanggal 20 Februari 2017 dan bertambah pada dini hari tanggal 21 Februari 2017 untuk beberapa lokasi. Jika dilihat pada tabel 2, total curah hujan harian tergolong ekstrim pada tanggal 20 Februari 2017 yang diukur pada pukul 07.00 LT tanggal 21 Februari 2017. Total curah hujan tertinggi terukur $159.6 \mathrm{~mm} / \mathrm{hari}$ di Pos Pengamatan Politeknik Negeri Bandar Lampung. Curah hujan sangat lebat (kategori BMKG > 100 $\mathrm{mm} /$ hari) terpusat di daerah Bandar Lampung dan Pesawaran.

Tabel 2. Curah hujan harian.

\begin{tabular}{|c|c|c|}
\hline $\begin{array}{l}\text { Stasiun / Pos pengamatn hujan } \\
\text { na }\end{array}$ & $\begin{array}{c}\text { Curah hujan (mm) } \\
20 \text { Februari } 2017\end{array}$ & $\begin{array}{c}\text { Kategori hujan } \\
\text { BMKG }\end{array}$ \\
\hline $\begin{array}{l}\text { Stasiun Meteorologi Maritim Panjang } \\
\text { Lampung Selatan }\end{array}$ & 80.5 & Lebat \\
\hline $\begin{array}{l}\text { Stasiun Meteorologi Radin Inten II } \\
\text { Lampung Selatan }\end{array}$ & 87.5 & Lebat \\
\hline $\begin{array}{l}\text { Stasiun Klimatologi Masgar } \\
\text { Pesawaran }\end{array}$ & 107.0 & Sangat Lebat \\
\hline $\begin{array}{l}\text { Pos Pengamatan Politeknik Negeri Bandar } \\
\text { Lampung }\end{array}$ & 159.6 & Sangat Lebat \\
\hline $\begin{array}{l}\text { Pos Pengamatan Kemiling } \\
\text { Bandar Lampung }\end{array}$ & 154.0 & Sangat Lebat \\
\hline Pos Pengamatan Negeri Katon, Pesawaran & 114.0 & Sangat Lebat \\
\hline Pos Pengamatan Tanggamus Pesawaran & 153.0 & Sangat Lebat \\
\hline Pos Pengamatan Pesisir Barat & 52.0 & Lebat \\
\hline Pos Pengamatan Belalau, Lampung Barat & 67.0 & Lebat \\
\hline Pas Pengamatan Balik Bukit, Lampung Barat & 39.5 & Sedang \\
\hline $\begin{array}{c}\text { Pos Pengamatan Lombok Seminung, } \\
\text { Lampung Barat }\end{array}$ & 14.0 & Ringan \\
\hline
\end{tabular}

Untuk wilayah Lampung Selatan dan Pesisir Barat, curah hujan masuk kategori lebat dimana kategori lebat BMKG berkisar antara 50-100 $\mathrm{mm} /$ hari. Untuk wilayah Lampung Barat, curah hujan bervariasi dari ringan hingga sedang menurut kategori BMKG.

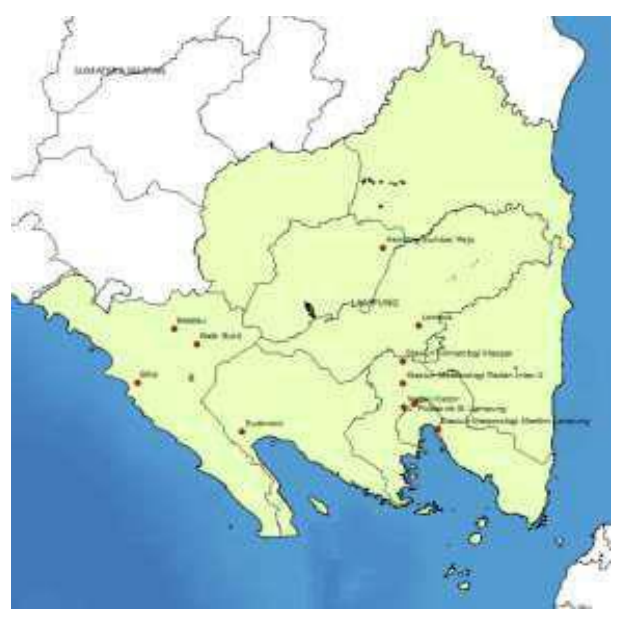

Gambar 4. Sebaran Pengamatan Hujan di Lampung

Dilihat pengukuran curah hujan pertiga jam dari Stasiun Meteorologi Radin Inten II Lampung, menunjukan hujan mulai turun rentang waktu 09.00 UTC - 12.00 UTC atau 16.00 LT - 19.00 UTC. Hujan terjadi lebih dari 12 jam. Curah hujan per tiga jam tertinggi diukur pada rentang waktu 12.00 UTC - 15.00 UTC. Jika dilihat dari grafik pada gambar 5, hujan turun dengan intensitas sangat lebat sesuai kategori BMKG > $20 \mathrm{~mm} / \mathrm{jam}$ dalam rentang waktu yang lama.

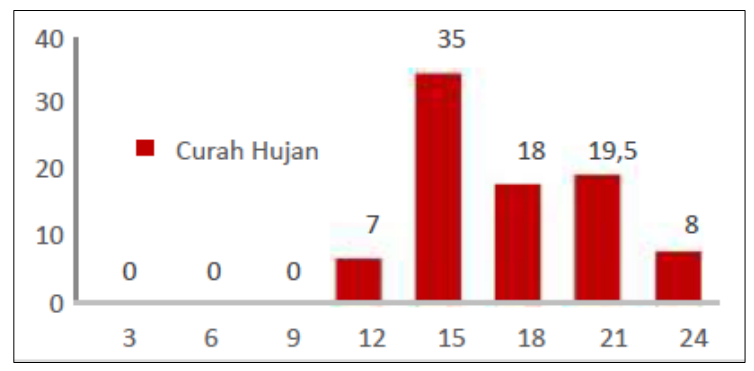

Gambar 5. Grafik curah hujan pertiga jam di Stsiun Meteorologi Radin Inten II.

\section{b. Analisis Satelit}

Grafik curah hujan pertiga jam menunjukan bahwa hujan penyebab banjir terjadi karena awanawan hujan berada di wilayah Lampung dalam rentang waktu yang lama. Hujan terjadi antara rentang $09.00-24.00$ UTC pada tanggal 20 Februari 2017. Awan-awan ini akan dianalisis menggunakan satelit cauaca Himawari-8 dengan melihat beberapa produk olahan. Hujan terjadi dominan pada malam hari waktu setempat, sehingga analisis tidak apat 
dilakukan dengan kanal visible. Produk-produk hasil olah citra satelit Himawari 8 yang digunakan untuk analisis dinamika atmosfer pada kejadian banjir di Lampung disesuaikan dengan kebutuhan analisis untuk malam hari.

Kanal utama yang digunakan untuk mendeteksi awan hujan adalah kanal 1R (IR $12.3 \mu \mathrm{m}$ ). Produk yang dihasilkan berupa citra infra merah penajaman (enhanced infrared) seperti pada gambar 6.

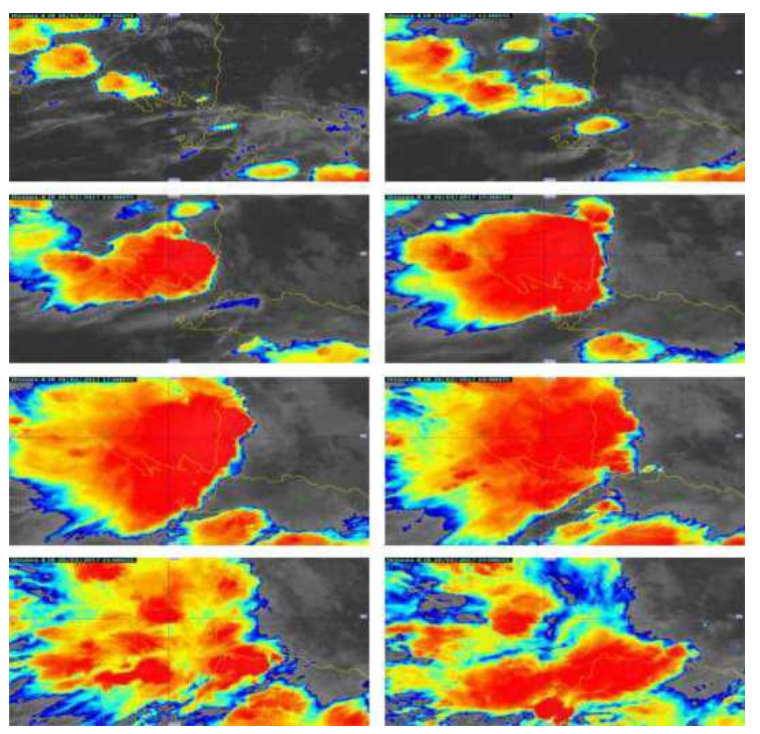

Gambar 6. Citra satelit IR $12.3 \mu \mathrm{m}$ citra penajaman (enhaced) pukul 09.00 UTC, 11.00 UTC, 13.00 UTC, 15.00 UTC, 17.00 UTC, 19.00 UTC, 21.00 UTC dan 23.00 UTC pada tanggal 20 Februari 2017.

Dari citra satelit dalam bentuk tampilan IR 12.3 $\mu \mathrm{m}$ dengan penajaman (enhanced infrared) di wilayah Lampung (lihat gambar 4), tertutup cakupan awan yang tebal disimbolkan dengan berwarna merah menyala. Awan tumbuh pertama kali didaerah barat hingga selatan Lampung pada pukul 09.00 hingga 13.00 UTC, kemudian berkembang dan menutupi hampir keseluruhan dari wilayah Lampung pada pukul 15.00 UTC hingga 19.00 UTC. Tutupan awan kemudian bergerak kearah selatan menuju daerah Banten dan DKI Jakarta pada pukul 23.00 UTC, tutupan awan ini juga yang menjadi penyebab banjir di daerah Jakarta dan sekitarnya pada tanggal 21 Februari 2017.

Untuk mengetahui suhu puncak awan dalam bentuk periode waktu ditampilkan dalam bentuk time series sejak terjadi hujan pukul 09.00 UTC hingga terjadi pukul 23.00 UTC pada dua titik pengamatan hujan yaitu di Stasiun Meteorologi Radin Inten II dan Stasiun Meteorologi Maritim Panjang. Untuk suhu puncak awan di Stasiun Meteorologi Radin Inten II (gambar 7a) terlihat suhu puncak awan mulai bergerak menuju sangat rendah sekitar pukul 09.00 UTC hingga 11.00 UTC, suhu berada dibawah $-60{ }^{\circ} \mathrm{C}$ mulai dari pukul 11.00 UTC hingga 21.00 UTC, bahkan suhu mencapai $\quad-90 \quad{ }^{\circ} \mathrm{C}$. Tidak jauh berbeda kondisinya dibanding suhu puncak awan di Stasiun Meteorologi Maritim Panjang (gambar 7b). Semakin rendah suhu puncak awan mendikasiakan bahwa awan tersebut telah terjadi pengembunan yang menjadi cikal bakal titik-titik hujan. Setelah titik-titik air turun, suhu pusat awan turun karena telah terjadi presipitasi berupa hujan. Awan yang berada di wilayah Lampung yang mempunyai suhu mencapai $\quad-90 \quad{ }^{\circ} \mathrm{C}$ teridentifikasi awan Cumolinimbus $(\mathrm{Cb})$ dimana suhu puncak awan $\mathrm{Cb}$ yaitu $\leq-50^{\circ} \mathrm{C}\left(223^{\circ} \mathrm{K}\right)$ (Manual SATAID, 2009).

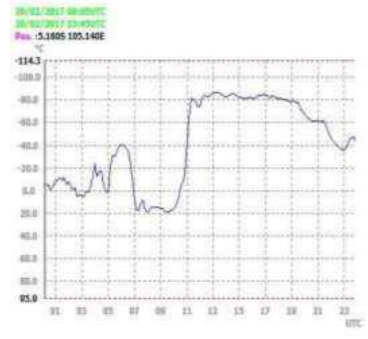

(a)

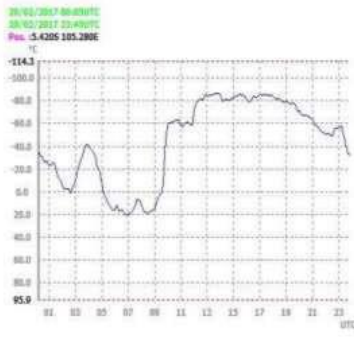

(b)
Gambar 7. Grafik times series suhu puncak awan pada tanggal 20 Februari 2017 di Stasiun Meteorologi Radin Inten II (a) dan Stasiun Meteorologi Maritim Panjang (b).

Hasil pengolahan data Himawari-8 enggunakan perangkat lunak Sataid GMSLPD pengolahan untuk wilayah Lampung dengan teknik RGB Night Microphysics disajikan pada gambar 9. Pola warna dihasilkan dari citra dengan Red (IR12.3 $\mu \mathrm{m}$ - IR10.4 $\mu \mathrm{m}$ ), Green (IR10.4 $\mu \mathrm{m}$ NIR3.9 $\mu \mathrm{m}$ ), Blue (IR $10.4 \mu \mathrm{m})$ sebagai komponen yang mengindikasikan pola keberadaan awan dengan melihat proses mikrofisisnya (Eumetsat, 2014).

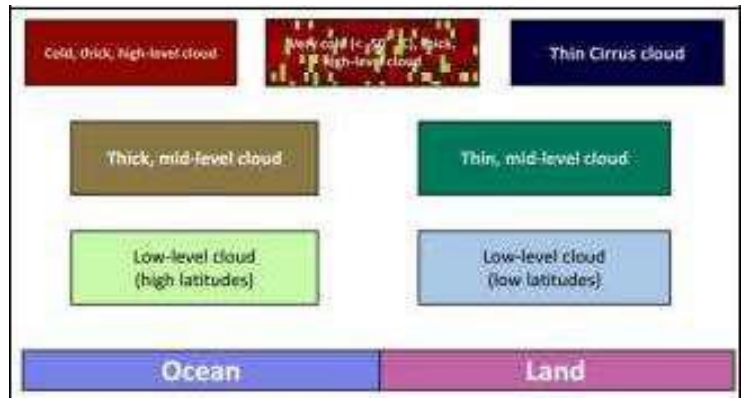


Gambar 8. Interpretasi Night Microphysics.
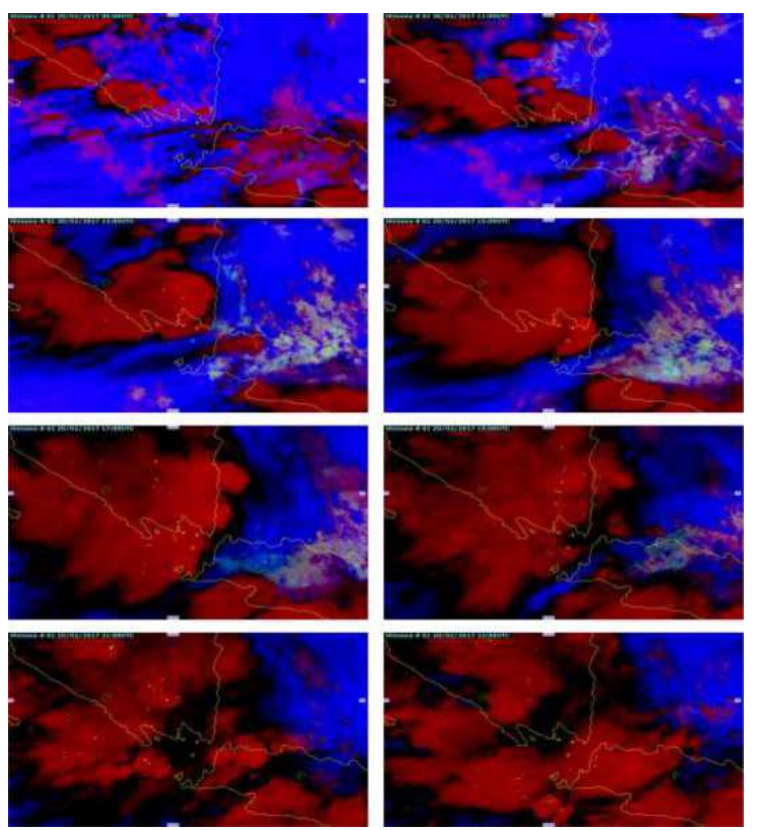

Gambar 9. Citra satelit produk Night Microphysics pukul 09.00 UTC, 11.00 UTC, 13.00 UTC, 15.00 UTC, 17.00 UTC, 19.00 UTC, 21.00 UTC dan 23.00 UTC pada tanggal 20 Februari 2017.

Pola warna merah menunjukan adanya proses mikrofisis, dimana semakin cerah warna merah menunjukan adanya proses yang makin besar dan suhu awan makin dingin. Pola merah cerah dengan bintik kuning menujukan bahwa area tersebut memiliki suhu yang angat rendah dibanding sekitarnya.

Pola bintik-bintik kuning mengindikasikan bahwa terdapat area overshooting pada awan. Pola biru tua menunjukan adanya awan-awan cirrus. Sedangkan pola warna merah muda menunjukan awan-awan rendah seperti stratus dan cumulus. Hasil pengolahan data Himawari 8 menggunakan teknik RGB Air Mass disajikan pada gambar 10. Pola warna dihasilkan dari citra dengan Red (WV6.2 $\mu \mathrm{m}$ - WV7.3 $\mu \mathrm{m}$ ), Green (IR9.7 $\mu \mathrm{m}$ - IR10.8 $\mu \mathrm{m}$ ), Blue (WV6.2 $\mu \mathrm{m})$. Pola warna hijau tua menunjukan kandungan massa udara hangat dengan kandungan uap air tinggi terdapat di wilayah Lampung. Uap air hangat inilah yang menjadi sumber utama pertumbuhan awan yang terangkat naik karena proses konvergansi sehingga tumbuh menjadi awan Cumulonimbus (Cb) yang cukup besar. Massa udara hangat yang memiliki kandung uap air tinggi ini terlihat hingga pukul 13.00 UTC (lihat gambar 10), sehingga pertumbuhan awan masih sangat intensif hingga pukul 15.00 UTC. Dari streamline terlihat massa udara hangat membentuk awan dikarenakan adanya konvergensi (lihat gambar 1b). Setelah itu, massa udara hangat dengan kandungan uap air tinggi mulai berkurang, massa udara pada wilayah lampung tetap hangat namun dengan sedikit kandungan uap air, hal inilah yang menyebabkan pertumbuhan awan tidak signifikan lagi dan cenderung mulai punah. Massa udara hangat dengan sedikit kandungan uap air dapat terlihat dengan warna hijau kekuning-kuningan (hijau lumut).

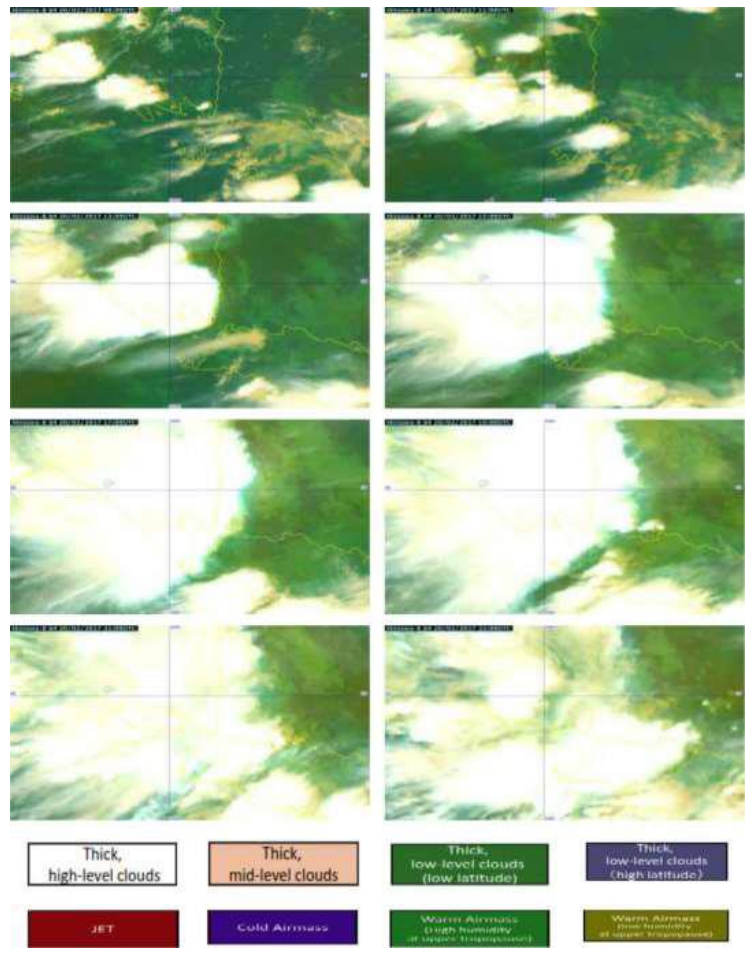

Gambar 10. Citra satelit produk Air Mass pukul 09.00 UTC, 11.00 UTC, 13.00 UTC, 15.00 UTC, 17.00 UTC, 19.00 UTC, 21.00 UTC dan 23.00 UTC pada tanggal 20 Februari 2017

Sebagai penguat analisis yang dilakukan sebelumnya, dapat digunakan produk HCAI hasil pengolahan data Himawari-8 yang merupakan pembaruan dari produk OCAI (Objective Cloud Analysis Information). Salah satu produk HCAI adalah penggolongan jenis awan terlihat seperti pada gambar 11. Pada mulanya pukul 09.00 UTC daerah Lampung didominasi oleh awan-awan rendah seperti Cumulus maupun Stratus. Kemudian awan Cumulonimbus yang berada di pesisir barat Lampung tumbuh dan berkembang kearah selatan dan tengah dari wilayah Lampung. Puncaknya antara rentang waktu 15.00 UTC hingga 18.00 UTC, dimana keseluruhan Lampung ditutupi awan Cumulonimbus yang sudah matang (ditandai dengan awan Cirrus 
sebagai anvil). Awan Cumulonimbus ini kemudian bergerak lalu terpisah-pisah mengarah selatan dan membentuk awan baru di daerah Banten dan DKI Jakarta.

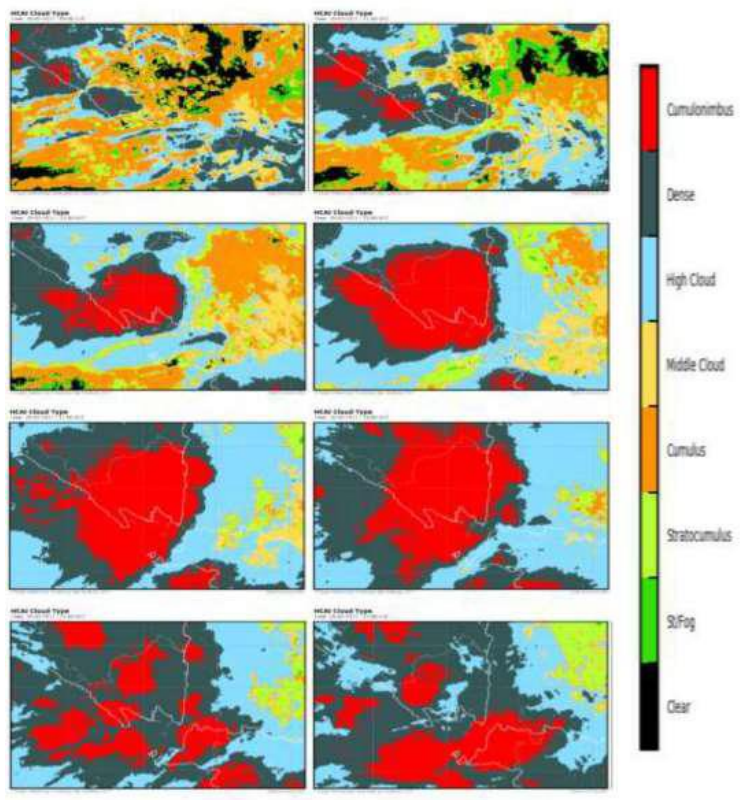

Gambar 11. Citra satelit produk HCAI pukul 09.00 UTC, 11.00 UTC, 13.00 UTC, 15.00 UTC, 17.00 UTC, 19.00 UTC, 21.00 UTC dan 23.00 UTC pada tanggal 20 Februari 2017

Hasil analisis angin gradien pada tanggal 20 Februari 2017 menunjukan adanya dua pusat tekanan rendah di barat dan selatan Lampung dan sirkulasi Eddy di timur dengan menyebabkan terdapatnya daerah perubahan arah angin (shearline) dan pertemuan aliran massa udara (konvergensi) di wilayah samudra barat Lampung hingga Lampung bagian barat dan selatan.

Kejadian banjir dilaporkan terjadi pada malam tanggal 20 Februari 2017 dan dini hari tanggal 21 Februari 2017 pada beberapa lokasi. Curah hujan harian tergolong ekstrim pada tanggal 20 Februari 2017 yang diukur pada pukul 07.00 LT tanggal 21 Februari 2017. Total curah hujan tertinggi terukur $159.6 \mathrm{~mm} / \mathrm{hari}$ di Pos Pengamatan Politeknik Negeri Bandar Lampung. Curah hujan sangat lebat (kategori BMKG > $100 \mathrm{~mm} / \mathrm{hari}$ ) terpusat di daerah Bandar Lampung dan Pesawaran. Jika dilihat pengukuran curah hujan pertiga jam dari Stasiun Meteorologi Radin Inten II Lampung menunjukan hujan mulai turun rentang waktu 09.00 UTC - 12.00 UTC atau 16.00 LT - 19.00 UTC. Analisis citra satelit menunjukan adanya kumpulan awan dengan suhu puncak yang sangat dingin, teknik RGB menggunakan identifikasi mikrofisis atmosfer pada malam hari (Night Microphysics) dan sebaran massa udara (Air Mass) menunjukan adanya proses mikrofisis yang intensif serta aliran massa udara penyebab awan hujan yang tumbuh dan meluas di wilayah Lampung sebelum dan saat terjadinya banjir. Hasil produk olahan HCAI (High-resolution Cloud Analysis Information) menunjukan awan didominasi oleh awan Comulonimbus $(\mathrm{Cb})$ dan awan konvektif padat (Dense Cloud).

\section{DAFTAR PUSTAKA}

Eumesat.2014. Training RGB. Diakses pada http://www.eumetrain.org/RGBguide/rgb s.html

Harsa, 2011. Pemanfaat SATAID Untuk Analisis Banjir dan Putting Beliung: Studi Kasus Jakarta

Dan Yogyakarta. Jurnal Meteorologi dan Geofisika vol 12, 197-205.

JMA. 2015. Himawari User's Guide. Diakses pada http://www.jmanet. go.jp/msc/en/support/index.html.

Kushardono, D. 2012. Kajian Satelit Penginderaan Jauh CuacaGenerasi Baru Himawari 8 dan 9. Jurnal Inderaja Vol. 3 No.5, Desember 2012.

Manual Sataid. 2009. Jakarta: BMKG

Pandjaitan, B dan Andersen, P. 2015. Pemanfaatan Data Satelit Cuaca Generasi Baru Himawari 8 Untuk Mendeteksi Asap Akibat Kebakaran Hutan Dan Lahan Di Wilayah Indonesia (Studi asus:Kebakaran Hutan Dan Lahan Di Pulau SumateraDan Kalimantan Pada Bulan September 2015)

Puslitbang BMKG. 2009. Kajian Cuaca Ekstrim di Wilayah Indonesia. Laporan Penelitian, Pusat Penelitian dan Pengembangan, Badan Meteorologi Klimatologi dan Geofisika, Jakarta.

Sebastian, L. 2008. Pendekatan Pencegahan Dan Penanggulangan Banjir. Jurnal Dinamika Teknik Sipil, 8(2), 162-169.

Tanaka, Y. 2009. SATAID-Powerful Toolfor Satellite Analysis. RSMC Tokyo- 
Typhoon Center, Japan Meteorol ogyAgency (JMA).

Tribun Lampung. 2017. BREAKING NEWS:

Banjir di Pesawaran, Bocah 10 Tahun

Tewas Tertimpa Perabotan. 